\title{
Incentivando meninas do ensino médio à área de Ciência da Computação usando o Scratch como ferramenta
}

\author{
Wesckley Faria Gomes, Carolina Santana Louzada, Maria Augusta \\ Silveira Netto Nunes, Edilayne Meneses Salgueiro, Beatriz Trinchão \\ Andrade \\ ${ }^{1}$ Departamento de Computação-DCOMP \\ Universidade Federal de Sergipe (UFS)- Aracaju,SE- Brasil \\ wesckley.gomes@gmail.com, carolina.louzada@hotmail.com,
gutanunes@gmail.com, edilayne@ufs.br, beatriz@ufs.br
}

\begin{abstract}
In order to promote proper support strategies, it is necessary to understand the factors that make women ingress and leave the computing field. In this work the Scratch programming language was used in order to increase the interest of high school girls in computing, through its application on teaching chemistry, physics and mathematics. Besides teaching them basic programming concepts, it was also possible to help them pedagogically in exact sciences. This article reports the experience gained in teaching Scratch to these girls. As result, it was noticed an important need to guide female students correctly regarding existing careers in the field.
\end{abstract}

Resumo. A fim de promover estratégias de fomento adequadas, é necessário compreender os fatores que levam as mulheres a entrarem e saírem do campo da computação. Neste trabalho, a linguagem de programação Scratch foi utilizada com o objetivo de aumentar o interesse de meninas do ensino médio na área por meio de sua aplicação no ensino de química, física e matemática. Além de ensiná-las conceitos básicos de programação também foi possível ajudá-las pedagogicamente em ciências exatas. Este artigo relata as experiências sobre o ensino e aprendizagem de Scratch para essas meninas. Como resultado, verificou-se uma importante necessidade de orientar as estudantes corretamente a respeito das carreiras existentes na área.

\section{Introdução}

O interesse crescente no incentivo de entrada de mulheres na área computacional não é só uma tentativa de igualar e entender as diferenças entre os gêneros, mas principalmente de suprir a necessidade de profissionais capacitados na área de computação. De acordo com a Brasscom (Associação Brasileira de Empresas de Tecnologia de Informação e Comunicação, 2014) estima-se que no ano de 2014 haverá um déficit de 45 mil profissionais de TI. Por outro lado, de acordo com a PNAD (Pesquisa Nacional por Amostra de domicílios) do Instituto Brasileiro de Geografia e Estatística (IBGE, 2009), as mulheres no Brasil ocupam 20\% dos empregos relacionados ao campo. No âmbito internacional, segundo o projeto Ada Initiative 
(2011) as mulheres representam $2 \%$ do total da comunidade de software aberto e $10 \%$ dos editores do Wikipédia.

Binkerd (2000) e Moore (2002) observaram que os homens são mais orientados tecnologicamente do que as mulheres durante a infância. Em união a essa questão existe o fato que os temas de diversas tecnologias tem como foco o público masculino. Os autores afirmam que as meninas na escola possuem uma menor autoestima quando se trata de entendimento na área matemática e tecnológica.

Considerando as diversas razões para que as mulheres entrem ou saiam da área de computação, diversas organizações e instituições desenvolvem estudos a fim de fomentar o ingresso de mulheres na computação e evitar a evasão daquelas que já estão na área. Segundo Louzada e outros (2014), dentre os artigos publicados a respeito de mulheres na área da computação, $41 \%$ destacam métodos e estratégias utilizadas em instituições para incentivar e evitar a evasão e $20 \%$ tratam de relatos de experiência de professores ou estudantes da área. Alguns dos artigos destacam a importância de ensino de programação para o desenvolvimento de habilidades para resolução de problemas.

Fazendo parte das diversas Instituições que desenvolvem esses estudos e projetos, a Universidade Federal de Sergipe através de uma iniciativa nacional chamada Meninas e Jovens Fazendo Ciências Exatas, Engenharias e Computação, está implementando um projeto de extensão com o objetivo de fomentar e evitar a evasão das mulheres nessa área. Para incentivar a entrada de mulheres em cursos de Ciência da Computação, Sistemas de Informação e Engenharia da Computação, algumas ações foram realizadas com meninas do ensino médio, para introduzir conceitos $\mathrm{e}$ competências da área de Computação.

Como uma das etapas desse projeto, três meninas do $1^{\circ}$ ano do Ensino Médio participaram de um curso de introdução à programação. Além de introduzir conceitos de pensamento computacional, as alunas foram incentivadas a criar e apresentar novos conhecimentos para os demais alunos da escola. Os jovens são naturalmente curiosos, mas como afirma Scaico e outros (2013) o ensino para novatos tem que usar uma metodologia que os mantenham engajados e motivados para aprender.

Este trabalho apresenta os resultados das ações de práticas de programação realizadas com a ferramenta Scratch em uma escola de ensino médio. Os conceitos de programação explorados pelas alunas são apresentados na Seção 2. Outros trabalhos relacionados ao ensino de programação para estudantes em idade escolar são discutidos na Seção 3. A Seção 4 apresenta o método utilizado neste trabalho para despertar o interesse por Computação. A partir dessas ações, os resultados obtidos são detalhados na Seção 5 e as considerações finais apresentadas na Seção 6.

\section{Ensino de programação com Scratch}

O Scratch é uma ferramenta desenvolvida pelo Massachusetts Institute of Technology (MIT) com intuito de introduzir a programação de computadores para jovens sem conhecimento aprofundado da área. Resnick e outros (2009) relataram que a ferramenta foi concebida com o objetivo de ensinar programação para qualquer idade. Os autores basearam-se nas ideias seminais de Papert, onde jovens poderiam programar computadores de uma forma lúdica, assim como se tornar fluente em novas tecnologias.

Com esse intuito, a programação no Scratch envolve conceitos de Computação Criativa, onde os jovens desenvolvem conhecimentos computacionais com base na 


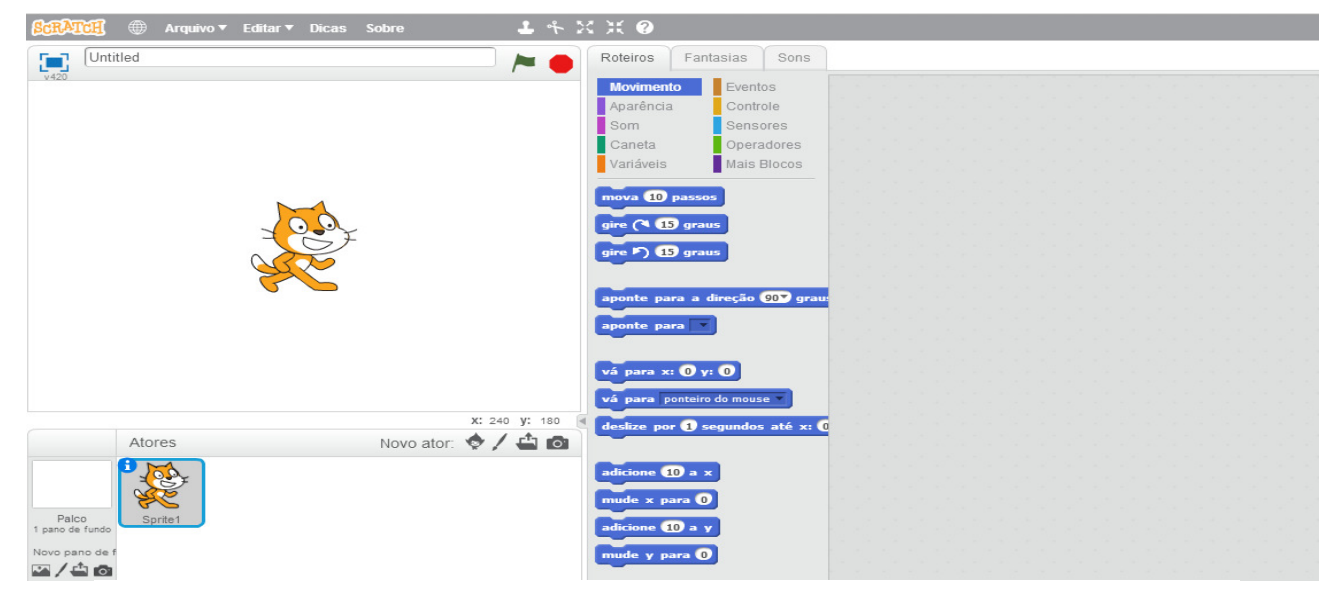

Fiqura 1 - Tela inicial Scratch

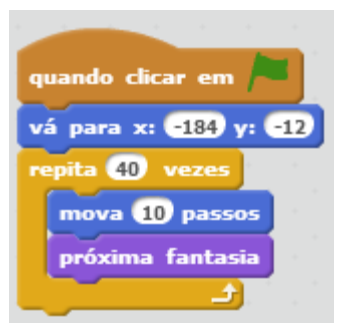

Figura 2 - Exemplo de um roteiro em Scratch

criatividade, imaginação e interesses. Com ela é possível desenvolver animações, jogos e histórias interativas sem a necessidade de conhecimento aprofundado em programação. Segundo Monroy e Resnick (2008), essa abordagem facilita o aprendizado dos alunos, que não apenas aprendem os conceitos da computação, mas desenvolvem algumas habilidades como: pensamento criativo, comunicação efetiva, análise crítica, experimentação sistemática, design interativo e aprendizagem contínua.

O ambiente de programação do Scratch utiliza a metáfora da criação de uma peça de teatro. $\mathrm{O}$ programador deve criar roteiros para uma peça. $\mathrm{O}$ ambiente define áreas onde o programador deve escolher as ferramentas que vai utilizar: palco, onde é visualizado o conteúdo produzido; atores, onde ficam dispostos os atores do palco; e uma área dividida em três abas: roteiros, onde ficam todos os blocos de instruções disponíveis; fantasias, onde o aluno pode editar a fantasia do personagem ou até mesmo criar uma nova fantasia; sons, onde o aluno pode editar ou criar um novo som para o personagem. No exemplo da Figura 1, o ator "gato" pode ser associado a eventos, através de roteiros, representados por uma sequência de blocos em azul.

A ferramenta Scratch utiliza a metodologia "arrastar e soltar", que ao invés de utilizar código em formato de texto, define um programa como um conjunto de blocos que representam comandos (Figura 2). Esses blocos podem ser arrastados e dispostos de acordo com a ordem em que serão executados. Os blocos são divididos em grupos que representam diferentes recursos de programação, como o tratamento de eventos, movimento dos personagens e estruturas de controle computacionais, como sequência, repetição e estruturas condicionais. Com o intuito de facilitar o aprendizado, os blocos são concebidos de forma que possam ser encaixados a outros, como podem ser observados na Figura 2. Dessa forma, deixam mais explícito o propósito de cada um, evitando assim erros de sintaxe. 


\section{Trabalhos relacionados}

Segundo Scalco e outros (2013), alguns países vêm reconhecendo a necessidade de atualizar seus sistemas educacionais com relação a educação em Computação. Os jovens tem necessidade de desenvolver fluência digital para dominar ferramentas computacionais. Os autores utilizaram o Scratch para introduzir conceitos de programação. Além do ensino do Scratch, os autores mobilizaram uma competição de programação posterior que serviu como uma forma de avaliar e levantar dados sobre as perspectivas em relação à área da Computação. Essa olimpíada aconteceu com base nos conhecimentos adquiridos sobre a linguagem Scratch. A escolha pelo ensino da linguagem Scratch para jovens do ensino médio se deu justamente

porque é uma ferramenta capaz de provocar a criatividade e o poder de exploração do programador e, principalmente, de criar situações capazes de lhes explicar o funcionamento das suas estruturas de uma maneira que lhe faça sentido. (SCAICO e outros, 2013).

Em uma outra ação, Scaico e outros (2012), também utilizaram o Scratch em um projeto de extensão, para incentivar alunos de ensino médio a entrarem no campo da computação. Em ambos os relatos os resultados foram satisfatórios, pois os alunos compreenderam a importância da computação no dia-a-dia e aprenderam mais sobre as atividades de um profissional de TI. Em Scaico e outros (2013), 80\% do total de alunos demonstraram vontade de continuar aprendendo outras linguagens de programação posteriormente. Já no projeto de Scaico e outros. (2012) 83,8\% dos alunos mostraram interesse em continuar a programar e $90,3 \%$ concordaram que as atividades os ajudaram a se interessar mais pela computação.

Andrade, Silva e Oliveira (2013), utilizaram o Scratch para desenvolver habilidades matemáticas com a construção de jogos. As práticas de programação foram realizadas em uma turma de $9^{\circ}$ ano do Ensino Fundamental. Segundo os autores, os alunos ficaram entusiasmados com o aprendizado de programação e os resultados com a aprendizagem de matemática foram perceptíveis, depois das ações.

Algumas outras iniciativas utilizam outros paradigmas de linguagens de programação para o ensino médio. Marques e outros (2011) fazem uma descrição e levantamento estatístico de alunos do ensino médio que aprenderam programação com a linguagem Phyton através de jogos dinâmicos. A escolha por essa linguagem se deu por ser considerada pelos autores simples e poderosa para o objetivo pretendido. Ao final do trabalho verificou-se a satisfação dos alunos quanto à oficina e que realmente o recurso utilizado foi muito motivador para todos os alunos participantes. No entanto, a sintaxe de Python pode se tornar uma barreira para alunos iniciantes.

Malan e Leitner (2007) utilizaram o Scratch para ensinar iniciantes da programação da Harvard Summer School's Computer Science. Como o curso de programação envolvia outras linguagens, utilizou-se um método comparativo para entender a influência do Scratch na aprendizagem de JAVA. A linguagem JAVA é usada nessa escola como parte do curso introdutório de programação. No entanto, para muito estudantes iniciantes, a lógica da programação é complexa, o que dificulta mais a aprendizagem da linguagem JAVA. No sentido de desenvolver essa habilidade o Scratch recebeu avaliação positiva pelos alunos. A experiência relatada mostrou que $76 \%$ dos alunos do curso expostos ao Scratch foram influenciados positivamente ao aprenderem JAVA. Esse dado mostra que a linguagem Scratch é um recurso valioso 
para construir o pensamento lógico-matemático dos estudantes iniciantes em programação. Consequentemente, sem a preocupação com detalhes de sintaxe, a compreensão do pensamento computacional é facilitado com as novas abordagens de ensino de programação do Scratch.

Resnick e outros (2009) afirmam que além de Harvard, as universidades de Califórnia e Berkeley também usam Scratch como forma de incentivar e introduzir a programação para seus alunos. Mais do que uma ferramenta inicial de ensino da programação para futuros cientistas e engenheiros da computação, Scratch é um recurso que auxilia na educação e expressão de jovens e crianças.

\section{Metodologia utilizada}

Com o objetivo de incentivar meninas para os cursos de Ciências Exatas como Engenharia e Computação, elaborou-se uma ação para introduzir o ensino de programação no ensino médio. O ensino de Scratch foi iniciado, através de um projeto de extensão, em uma escola pública do estado de Sergipe.

A estratégia foi introduzir programação nas aulas de química, física e matemática, por meio da produção de animações e documentos interativos contendo os assuntos abordados em sala. A proposta inicial, apresentada neste trabalho, foi de realizar uma experiência com apenas três meninas, usada como projeto-piloto, e a partir da análise dos resultados obtidos, dar continuidade com o restante da turma.

A organização do trabalho se deu em 4 etapas:

i. Identificação do perfil das alunas;

ii. Elaboração de um plano pedagógico;

iii. Ensino da linguagem Scratch para as alunas;

iv. Produção de animações e documentos interativos, seguindo o plano pedagógico.

A primeira etapa de identificação do perfil das meninas, foi baseada em um questionário com algumas perguntas voltadas para a computação e também perguntas de cunho geral. A ideia foi mensurar o quanto de conhecimento as meninas possuíam sobre a área e seus interesses pela tecnologia. Alguns resultados do questionário foram: (i) a faixa etária das meninas eram entre quinze e dezesseis anos; (ii) as três se identificavam com pelo menos uma matéria de exatas na escola; (iii) apenas uma não tinha ouvido falar em ciência da computação; (iv) apenas uma já havia participado de um projeto na área de exatas; (v) as três não sabiam como funcionava um programa de computador; (vi) ciência de computação não era uma opção de curso para elas; (vii) nenhuma sabia como funcionava um computador, mas se mostraram motivadas para aprender a programar um.

Para a segunda etapa, contou-se com a participação de uma professora de química (também bolsista do projeto), a qual elaborou o plano pedagógico, separando os temas abordados em sala de aula de forma que pudessem ser criadas animações no Scratch para serem utilizadas como mais um recurso para auxílio às aulas ministradas.

A terceira etapa dedicou-se ao ensino dos conhecimentos básicos de computação. Scratch foi utilizado como linguagem de programação. O curso teve uma carga horária de 10 horas, sendo ministrado em aulas de 2 horas de duração. Os objetivos principais foram apresentar o curso de Ciência da Computação mostrando alguns vídeos motivacionais e ensinar as principais estruturas de uma linguagem de 

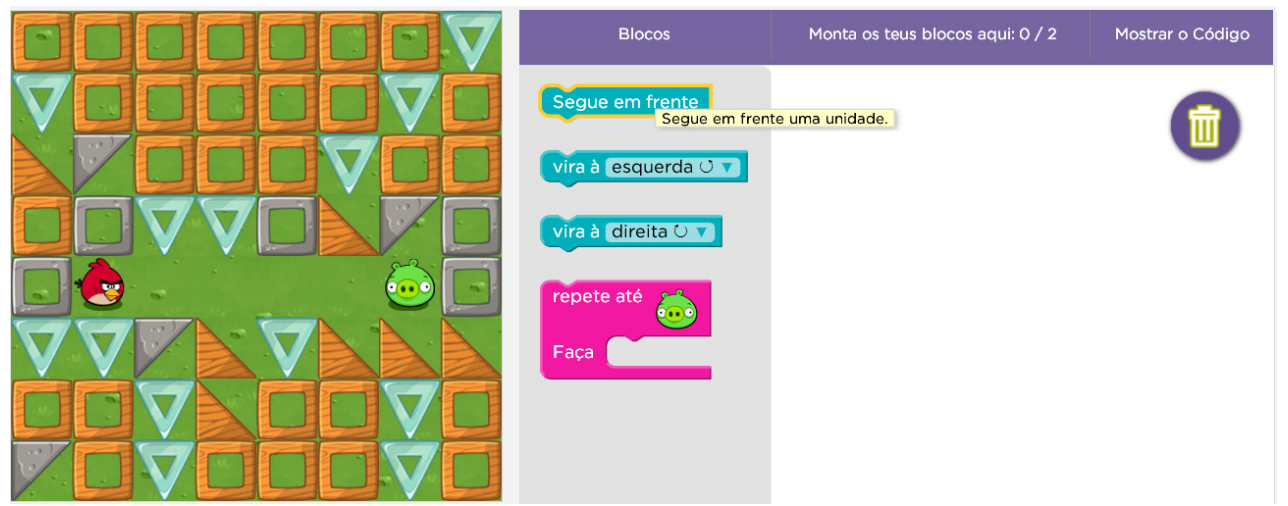

Figura 3 - Interface de Jogo Angry Birds. Fonte: (Code, 2014)

programação, a partir de jogos. De forma a respeitar o ritmo de aprendizagem de cada aluna, o conteúdo do curso foi separado em teoria e prática, onde alguns exercícios foram realizados em sala e outros passados para serem feitos em casa. As meninas se mostraram bem empenhadas em aprender a programar e entusiasmadas com a perspectiva de elas mesmas produzirem os jogos e animações.

As aulas iniciaram com a apresentação de alguns vídeos motivacionais disponíveis no projeto Hora do Código (Code, 2014). Através de jogos, como o da Figura 3, elas aprenderam conceitos iniciais de programação, como as estruturas de sequência, repetição e estruturas condicionais. Esse jogo utiliza a mesma metodologia do Projeto Scratch para programar (arrastar e soltar), e tem como objetivo movimentar um personagem em um terreno através de comandos representados pelos blocos.

A quarta etapa dedicou-se a produção das mídias pelas participantes. Com os conhecimentos aprendidos no curso, elas construíram animações e documentos interativos, com Scratch, de acordo com o plano pedagógico proposto pela professora.

\section{Resultados}

Após o término das etapas descritas na Seção 4 deste trabalho, as meninas foram desafiadas a construir suas próprias animações utilizando os conhecimentos adquiridos no curso através da ferramenta Scratch. As participantes tiveram uma semana para realização das atividades, onde elas teriam que construir algo relacionado com o plano pedagógico elaborado. Cada uma ficou responsável por uma matéria (química, física e matemática) e elas ficaram livres para escolher sobre qual assunto construir a animação.

Ao final da semana foi realizada uma reunião com os participantes do projeto para apresentação das animações realizadas pelas participantes. A Tabela 1 mostra a divisão das matérias e assuntos abordados pelas participantes.

As meninas ficaram entusiasmadas com a possibilidade de construir algo útil para elas, e de efetivamente colocar em prática o que aprenderam de computação. Elas

Tabela 1 - Divisão dos assuntos abordados

\begin{tabular}{lll}
\hline Participante & Matéria & Assunto \\
\hline Participante 1 & Matemática & Introdução à Trigonometria \\
Participante 2 & Física & Leis de Newton \\
Participante 3 & Química & Fenômenos \\
\hline
\end{tabular}


tiveram muita criatividade na construção das animações, se preocuparam com detalhes, principalmente com a parte visual, buscando imagens na Internet e até mesmo construindo as próprias. É importante ressaltar que elas tentaram utilizar ao máximo os recursos aprendidos nas aulas como estruturas de controle, interação com o usuário, emissão de sons e mudança de fantasia.

A Figura 4 apresenta o resultado do Scratch desenvolvido pela participante 1, a qual criou uma animação sobre a trigonometria ${ }^{1}$. A ideia da participante foi mostrar a classificação dos triângulos quanto ao ângulo: retângulo, obtusângulo e acutângulo, com ênfase nas estruturas do triângulo retângulo. Foram exploradas principalmente as estruturas de controle e eventos. A Figura 5 mostra a animação realizada pela participante 2, cujo objetivo foi explicar as leis de Newton ${ }^{2}$ : (a) princípio da inércia; (b) princípio fundamental da dinâmica; (c) princípio da ação e reação. Já a Figura 6, apresenta a animação construída pela participante 3. O tema escolhido por essa última participante foi sobre fenômenos físicos e químicos ${ }^{3}$. Nessa animação, uma menina aparece explicando os fenômenos à medida que vão aparecendo imagens com exemplos desses fenômenos. É importante ressaltar que as imagens das meninas utilizadas foram produzidas por um aluno da escola.

As animações em Scratch foram produzidas e publicadas no próprio site do Scratch (MIT, 2014). Os resultados apresentados foram relevantes, onde as participantes mostraram uma parte do conhecimento que adquiriram sobre como funciona um programa de computador. Ao término das apresentações, solicitou-se a cada participante que relatasse toda a experiência dessa etapa do projeto, com o intuito de extrair informações sobre o que aprenderam, as dificuldades encontradas e como este projeto mudou a visão delas em relação à computação. A Tabela 2 retrata alguns relatos das participantes, elas deram feedback relevante para as próximas etapas do projeto.

Diante dos relatos expostos pelas meninas, pôde-se perceber que elas se interessaram pelo tema, gostaram da experiência, e consideraram algo importante e útil para vida delas. É importante ressaltar, que dentro de uma pequena amostra com três meninas, uma delas, considera que computação pode sim ser uma opção de curso para ela.

\section{Considerações finais}

O projeto descrito neste trabalho teve como objetivo o incentivo de meninas do ensino médio no curso de computação por meio do ensino dos conceitos básicos de programação com o uso da linguagem Scratch. Pode-se dizer que os resultados alcançados foram satisfatórios, pois pôde-se observar um retorno do trabalho através do feedback e produção das participantes. Com ele, foi possível estimular a capacidade de raciocínio das alunas do ensino médio, além de despertar mais uma possibilidade de carreira profissional pouco divulgada nas escolas

Os primeiros programas em Scratch criados eram totalmente sequenciais, sem utilização de estruturas de repetição, o que foi mudando ao longo das demais práticas. Foi difícil para elas visualizarem inicialmente um programa de computador com estruturas de repetição e condicionais, mas todas conseguiam abstrair programas de

\footnotetext{
${ }^{1}$ http://scratch.mit.edu/projects/24342845/

2 http://scratch.mit.edu/projects/24342944/

${ }^{3}$ http://scratch.mit.edu/projects/24342921/
} 


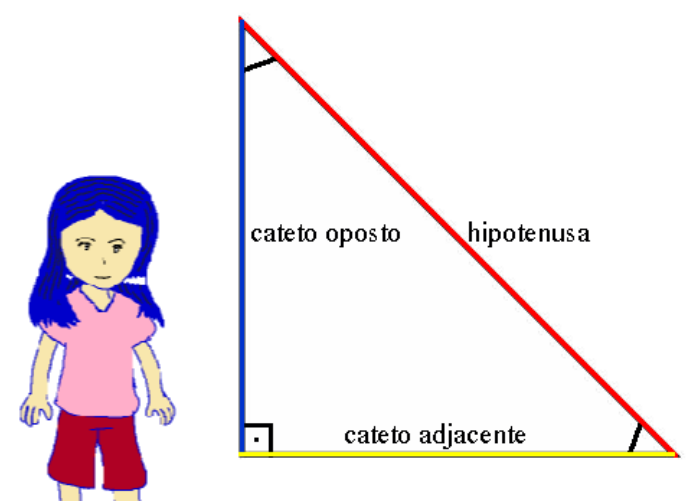

Figura 4 - Animação desenvolvida pela participante 1

$2^{\circ}$ Lei de Newton

Princípio fundamental da Dinâmica

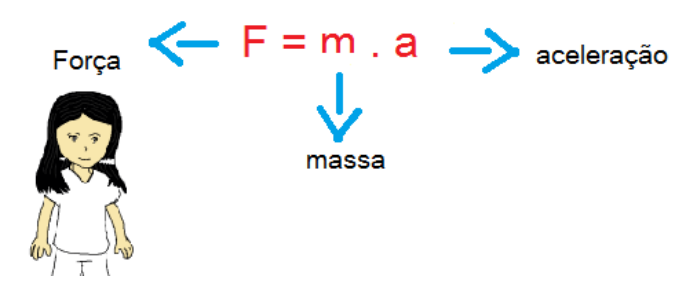

Figura 5 - Animação desenvolvida pela participante 2

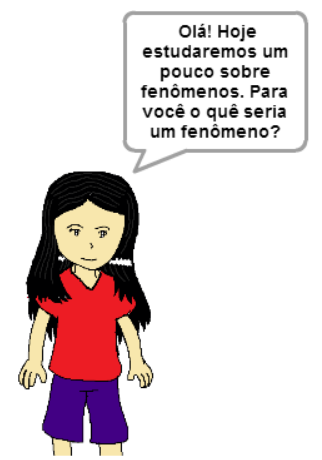

Figura 6 - Animação desenvolvida pela participante 3

forma sequencial como solução de um problema. Com as mídias produzidas pelas meninas, pôde-se observar uma evolução no pensamento computacional delas, com relação as demais estruturas de programação.

O conteúdo apresentado neste trabalho serve de feedback e base inicial para a continuação do projeto que visa o incentivo de meninas na área da computação. Após os resultados positivos encontrados, espera-se que o ensino do Scratch para o restante da turma obtenha sucesso e, que os resultados possam ser mais representativos. E que dessa forma, o projeto possa ser multiplicado no país visando incentivar outras jovens a seguir a carreira da computação no Brasil. 
Tabela 2 - Relatos de experiência das participantes

\begin{tabular}{|c|c|}
\hline Participante & Relato \\
\hline Participante 1 & $\begin{array}{l}\text { (...) Primeiramente, antes tomava isso como algo super complicado, fora do meu } \\
\text { alcance. Agora, ainda tenho como algo difícil, porém não um "bicho de sete } \\
\text { cabeças"... Apesar d saber que estamos somente no básico. } \\
\text { (...) Ao conhecermos a interface do Scratch foi algo legal, interessante, mas } \\
\text { também... não digo assustador, porque não foi... diferente de uma maneira que você } \\
\text { pensa que pode não aprender! No entanto, pelo menos o básico, nós conseguimos } \\
\text { absorver bem e até montar um! } \\
\text { (...) Embora o Scratch seja uma ferramenta fácil, alguns recursos se encontram de } \\
\text { maneira difícil por falta de conhecimento na área. De fato é legal, divertido e } \\
\text { instigante e que também precisamos ter conhecimentos básicos sobre programação, } \\
\text { no mínimo!! Porém, com relação a praticidade, como já foi citado anteriormente, é } \\
\text { necessário conhecimentos sobre computação que ainda não temos, pois a questão } \\
\text { é: montar um Scratch não é difícil desde que se tenha o conhecimento necessário, } \\
\text { como por exemplo, as variáveis, que são muito utilizadas, se quisermos fazer algo } \\
\text { fora do básico. }\end{array}$ \\
\hline Participante 2 & $\begin{array}{l}\text { (...) Acabei conhecendo um pouco do que é "Ciência da Computação", mas } \\
\text { gostaria de saber mais. Percebi também que existem poucas mulheres no ramo e } \\
\text { que de certa forma são mal vistas. Nas aulas com o professor aprendi um pouco da } \\
\text { lógica a ser usada para fazer uma programação. A ferramenta Scratch é uma } \\
\text { maneira legal de se apresentar algo ou aprender. } \\
\text { (...) Sinceramente, por não saber o que quero fazer depois do colégio, o curso de } \\
\text { ciência da computação pode ser mais uma opção, acho interessante que tenha mais } \\
\text { comunicação entre as professoras do curso e nós alunos. Perguntei as orientadoras } \\
\text { como decidiram fazer esse curso e acabei que me interessando mais. }\end{array}$ \\
\hline Participante 3 & $\begin{array}{l}\text { (...) Antes de tudo, gostaria de comentar que minha visão sobre a Computação } \\
\text { pode-se dividir em duas partes: Antes do Projeto e Atualmente, atuando no Projeto. } \\
\text { Tenho que confessar que não tinha muito conhecimento sobre a área, achava que } \\
\text { tratava-se de algo muito complicado, principalmente por envolver as Exatas. Hoje, } \\
\text { vejo que Programar exige atenção, persistência, criatividade e lógica, sendo desse } \\
\text { modo um exercício para o desenvolvimento do raciocínio e aprendizagem de } \\
\text { superar os desafios. } \\
\text { (...) De início, tivemos dificuldades em chegar aonde queríamos, pois nem sempre } \\
\text { conseguíamos encontrar as imagens que desejávamos para a produção, além de não } \\
\text { termos um amplo conhecimento sobre os comandos da ferramenta, desse modo, a } \\
\text { inexperiência foi um dos motivos do nosso embaraço. Porém, aos poucos fomos } \\
\text { nos acostumando e percebendo que o ato de programar é um bom exercício para } \\
\text { o cérebro, sendo importante para o desenvolvimento da aprendizagem e da } \\
\text { superação de desafios. De certa forma, é trabalhoso para criar, mas também é } \\
\text { divertido. } \\
\text { (...) Em um primeiro momento acreditei que o Scratch era bem simples de criar e } \\
\text { que não encontraria muitas dificuldades com a produção, porém, vejo que o } \\
\text { desenvolvimento depende do conhecimento e do domínio que se tem sobre a área e } \\
\text { dos recursos disponibilizados. }\end{array}$ \\
\hline
\end{tabular}

\section{Agradecimentos}

Ao MCTI/CNPq/SPM pelo fomento ao projeto $\mathrm{N}^{\circ}$ 420160/2013-2, intitulado "Popularizando e fomentando o ingresso de meninas sergipanas na área de Ciência da Computação, EC e SI visando a crescente demanda de profissionais no contexto estadual, nacional e internacional de TI". Ao CNPq pelas bolsas ITI e Produtividade em desenvolvimento Tecnológico concedidas. À CAPES. 


\section{Referências}

Ada Initiative. (2011) "Who we are". Disponivel em: < http://adainitiative.org/aboutus/> último acesso em: 26 de Junho de 2014.

Andrade, M., Silva, C. e Oliveira, T. (2013) Desenvolvendo games e aprendendo matemática utilizando o Scratch. In: SBC - Proceedings of SBGames 2013, São Paulo.

Associação Brasileira de Empresas de Tecnologia da Informação e Comunicação (2014) "O Mercado de Profissionais de TI no Brasil". Disponível em: http://www.brasscom.org.br/brasscom/Portugues/detInstitucional.php?codArea=3\&c odCategoria $=48$. Acesso em: 20 de Julho de 2014

Binkerd, C. L. e Moore, M. D. (2002) "Women/minorities in computer science: where are they? no attention no retention.", In: CCSC: South Central Conference , v.17, n.5, New York.

Code (2014) Hora do Código. Página oficial. Disponível em:< http://code.org.>

Instituto Brasileiro de Geografia e Estatística. (2009) "Síntese de indicadores sociais: Uma análise das condições de vida da população brasileira ." In: PNAD ( Pesquisa nacional por Amostras de Domicílio). Disponível em:< http://www.ibge.gov.br/home/estatistica/populacao/trabalhoerendimento/pnad2011/d efault.shtm>. Acesso em:10 de Julho de 2014.

Louzada, C. S. et al. (2014) “Um mapeamento das publicações sobre o ingresso das mulheres na computação" In: CLEI 2014: Conferência Latino-americana em Informática - VI Congresso da Mulher Latino-americana na Computação. Montevidéu.

Malan, D. J. e Leitner, H. H. (2007) "Scratch for budding computer scientists", ACM SIGCSE Bulletin, v.39 n.1, New York, USA.

Marques, D. L. et al. (2011) "Atraindo Alunos do Ensino Médio para a Computação: Uma Experiência Prática de Introdução a Programação utilizando Jogos e Python." In: Anais do XXII SBIE - XVII WIE, Aracaju/SE.

Monroy, A. H. e Resnick, M. (2008) "FEATURE: Empowering kids to create and share programmable media". In: Interactions, v.15 n.2, New York, USA.

MIT (2014) Projeto Scratch. Página oficial. Lifelong Kindergaten, MIT Media Lab. Disponível em http://scratch.mit.edu/. Último acesso em 15 de julho de 2014.

Resnick, M. et al.(2009) "Scratch: Programming for All". In: Communications of ACM, v.52, n.11. New York.

Scaico, P. D., et al. (2012) "Relato da Utilização de uma Metodologia de Trabalho para o Ensino de Ciência da Computação no Ensino Médio" In: Anais do Congresso Brasileiro de Informática na Educação - XVIII Workshop de Informática na Educação, ISSN: 2316-6541, Rio de Janeiro.

Scaico, P. D., et al. (2013) "Ensino de Programação no ensino Médio: Uma Abordagem Orientada ao Design com a linguagem Scratch”. In: Revista Brasileira de Informática na Educação, v.21, n.2. 